\title{
A Proposed Harmonic Monitoring System for Large Power Users Considering Harmonic Limits
}

\author{
Rosalia Sinvula *, Khaled Mohamed Abo-Al-Ez@ and Mohamed Tariq Kahn \\ Department of Electrical, Electronic and Computer Engineering, Faculty of Engineering and the Built \\ Environment, Cape Peninsula University of Technology, Cape Town 7535, South Africa; \\ aboalezk@cput.ac.za (K.M.A.-A.-E.); khant@cput.ac.za (M.T.K.) \\ * Correspondence: 207080704@mycput.ac.za
}

Received: 13 July 2020; Accepted: 7 August 2020; Published: 1 September 2020

\begin{abstract}
Most power utilities within Southern Africa are faced with the challenges of harmonic distortion due to the high penetration of renewable energy sources (RES) and the use of electronic devices. There is an excessive total harmonic distortion (THD) measured at the point of common coupling (PCC). In this paper, a proposed harmonic monitoring system for large power users (LPUs) is developed. This proposed system considers harmonic limits of the individual and THD of the customers allowed injecting into the network, which should be part of the contractual electricity supply agreement (ESA). Hence, it will enable the monitoring of harmonic distortion to be smooth by determining whether the customer has passed or failed compliance for individual harmonic order and the THD of the voltage. The measurements of harmonic distortion are done using the Unipower power quality $(\mathrm{PQ})$ analyzers that are connected at different points within the industrial network. Measurements of harmonic distortion of an industrial site are compared to the simulation results performed by DIgSILENT software to validate the proposed harmonic monitoring system. Based on the validation results, it is recommended that the ESA between the power utilities and the customers should consist of the harmonic limits.
\end{abstract}

Keywords: harmonic distortion; harmonic monitoring; harmonic limit; electricity supply agreement; harmonic measurement

\section{Introduction}

Distribution networks have power quality (PQ) challenges that compromise their performance [1]. Harmonic distortion is one of the PQ challenges that are currently rising due to the increase of non-linear loads and renewable energy sources (RES) which form part of the power system [2-6]. To strengthen the PQ performance of the distribution network, it is important to study the harmonic distortion and its effects [1]. Many studies are concerned with PQ problems and solutions [7]. Different solutions on how to mitigate the harmonic distortion have been proposed and implemented in power systems [8-10]. Although different approaches of harmonic distortion mitigation have been ongoing with a shortcoming in the literature on how harmonic distortion can be monitored at the point of common coupling (PCC) through a contractual relationship between the utilities and the customers. Currently, the contractual electricity supply agreement (ESA) between the utilities and the customers places little emphasis on $P Q$. The utility must emphasize more on the continuity of power supply to the customers as the quality of power supplied by the utilities is a concern to the customers.

The responsibility of PQ must be well defined in contracts. The contracts should address the issues concerning PQ in a way that is understood by all parties. There are national, and international standards with limits of harmonic distortion (current and voltage distortion) [11-16]. Guidelines on how to check and set up the voltage quality framework are given [17-20]. Although harmonic 
limits are set within standards, it should be interpreted in the ESA, as well. Harmonic distortion has effects on the power system equipment [21-23]. The harmonic distortion effects depend on the sequence component types of harmonics that are present at the PCC. Positive and negative sequences of harmonics cause the heating of the conductors and the power transformers [9]. For the positive order harmonics, the harmonic currents rotate in the same direction as the fundamental frequency current. These harmonic currents cause overheating of the power system equipment, such as transformers and conductors, due to the addition of the current to the fundamental frequency current. The current becomes higher than the rated current. Negative sequence harmonics can cause induction motors to run in the reverse direction; while zero-sequence harmonics cause neutral currents to be larger than phase currents [9]. Due to the negative effects that harmonics can cause, both parties need to take part in drawing up a contract agreement.

Harmonic distortion effects can result in financial losses for industries when the electrical installation is been damaged or through premature aging of the equipment and system reliability [24]. When the system consists of higher losses, it results in financial losses, as well [25]. Power utilities need to investigate a penalty fee that needs to be charged for harmonic distortion. This fee is to be part of the monthly electricity bill as an added investment to reduce the financial losses met due to the effects of harmonic distortion [1,24-26].

Traditionally, utilities believed that harmonics were only caused by the customers, which is no longer the case as it was found that utilities have background harmonics. Utilities need to specify in contracts the percentage of harmonic distortion each customer is allowed to inject into the national grid. This requirement should also apply to electricity distributors. The national grid must be protected from harmonic distortion at the generation, transmission, and distribution side. The determined background harmonics at the PCC, it must be made known to the customers that are requesting for electricity supply connection at the PCC to take into consideration when designing their equipment. The total current/voltage harmonic distortion is well defined within standards [11-14] according to the voltage level at the PCC. It is a concern on how to allocate the total current harmonic distortion in the case where multiple customers are connected at the PCC.

The legal site of contracts on PQ should be defined similarly to the Notified Maximum Demand (NMD). For instance, large power users (LPUs) notify the electricity supply industries of their maximum demand before the end of the year based on their load forecasting model. There is a need to develop a concept and processes to be followed by PQ engineers and commercial engineers when drawing up a $P Q$ agreement. When utilities take measurements and verify the harmonic limit based on the limit set out in the ESA, it ensures that the customer knows who is responsible and which harmonic order is dominant. Today's PQ analyzers can measure the harmonic distortion of each harmonic order that forms part of the network. Power utilities or electricity supply industries should use the harmonic balancing network through the harmonic aggregation method [14]. The customers should invest in installing a statistical PQ analyzer that can be used in case of a dispute between the parties involved.

Most of the electricity companies and the large customers' loads are informing the utility of their harmonic content for the utility engineers to undertake harmonic studies before signing a connection agreement or ESA. However, the percentages of the allowable harmonic current that specific customer can inject into the grid should form part of the ESA. The contribution of this paper is to propose a harmonic monitoring system which could be used during the planning phase and setting up of an ESA between the utility and customers. This technical management of harmonics is well-known, however, the method on how it is administered in the ESA needs to be emphasized to reduce the financial losses caused by harmonic distortion. It is also pointed out that the customer's harmonic content needs to be a part of the required document which forms part of the application for electricity supply. It is a challenge to find the party that is violating the PQ or Total Harmonic Distortion (THD) when multiple customers are connected at the same PCC, especially when some customers have no PQ analyzers installed. Once the party that is violating the PQ is identified, the consequences should be negotiated according to the transmission and distribution codes of the specific country [27-29]. The harmonic limit 
allowed at the PCC should be one of the determining factors for the number of customers allowed at a certain PCC. The NMD is currently a yearly exercise for customers to notify the utility of any changes in their operations. However, the harmonic limit has become a concern, whereby the customer has to notify the utility once they increase or decrease the loads that are categorized as harmonic sources. Whether notifying the utility of the harmonic content should be a yearly exercise for the customer is still under investigation.

During the planning/design phase, harmonic studies must be conducted intensively to determine the number of customers to be connected at the PCC [30]. The vital aspect for today's network is to conduct harmonic monitoring and this can only be achieved when both parties involved are working together. Most utilities are installing monitoring equipment to measure the three-phase harmonic current and voltage distortion to aid detecting and mitigating the effects of harmonics [31]. Harmonics can be from the upstream (utility side) through background harmonics or downstream (customer side) through the installation of equipment that is injecting current harmonics.

The utility's responsibility is to ensure that PQ is well kept and meets the required standards at different operating and load conditions [32]. The rewards and penalties set on PQ and reliability need to be honored by both parties [33]. The harmonic emission level affects the cost of customers buying electricity. Thus, it can cause increases in network tariffs to mitigate these disturbances if not monitored well [34]. Many studies have developed a method for monitoring the PQ including harmonic distortion [32,35-44]; thus, there is a gap to monitor and manage harmonics as early as the planning phase and include the harmonic limits in contract agreements.

Broshi $[45,46]$ highlighted the three main purposes of PQ monitoring (statistics, contracts, and troubleshooting). Under the PQ contract, it was emphasized that, in sensitivity to PQ, customers may have a specific electrical power contract that outlines the smallest acceptable PQ level to be supplied by the utility. This is in line with our idea of focusing on LPUs as these are the customers who have several numbers of non-linear loads and should be treated differently when it comes to harmonic distortion monitoring. Utilities should be supplying these LPUs with a special ESA with specific harmonic limits guided by the standards. It is more general about how to monitor all PQ challenges.

However, it concluded that, although the measurement can be following the standards, this does not make it clear to decide who is responsible for causing certain PQ issues. This clearly shows that it is important to have the harmonic limits of the individual and THD documented in the contract to give a good sign of the responsible harmonic distortion through measurements. Applicable standards as a guideline were formed as a starting point for PQ analysis and analyzers to follow the manufacturer's specification to obtain expected results. Hence, the utility may formulate precise required limits suitable for a specific network. The raw data at a high sampling rate and accuracy are to be based on standards and regulations already in existence. However, the troubleshooting engineer would require more information for effective monitoring and analyzing abnormalities.

Yildirin et al. [47] developed an Internet-based PQ Monitoring System (IPQMS) that transmits real-time $P Q$ data over the internet. This is like PQ secure software used to get real-time data from the Unipower $\mathrm{PQ}$ analyzer used in this paper. The monitoring of $\mathrm{PQ}$ is currently done in real-time via the internet $[48,49]$.

Milanovic et al. [50] presented the findings on the international survey about the industry's practice of $\mathrm{PQ}$ monitoring. The distribution network is highly monitored than the transmission network, as they have more PQ challenges. The primary motivation for PQ monitoring is based on customer complaints. It highlighted that the distribution network needs to supply evidence of compliance for the regulator more than the transmission network. It highlighted that this PQ monitoring outcome results are mostly used internally by the utility, and few reports are given to the regulators. Therefore, these issues of harmonic distortion compliance need to become a priority for the regulators.

Good management of distribution network harmonic distortion needs the best monitoring system in place [30,31]. The harmonic monitoring system is a valuable tool to use to limit the harmonic distortion at the PCC. The monitoring system requires correct harmonic measurements using the correct 
measuring equipment for it to be effective [51,52]. The discussion of the harmonic measurement results between the parties is minimally done. The known solution used once the harmonic monitoring is conducted is a technical solution that takes a lengthy period to be agreed upon. This solution involves harmonic mitigation, the most well-known being through designing harmonic filters. The proposed monitoring system encourages the technical solution, as well as the financial solution, using the payment of penalties. Once the payment of penalties is effective, this will help to minimize the time for designing and implementing the technical solution after three consecutive months of notification of the harmonics exceeding the set limit in the ESA.

The harmonic distortion needs to be charged to effectively compensate for the harmonic losses, as the distribution network and the customer's equipment are negatively affected. This also led to the excessive cost of power supply to the end-users for which the cost could be recovered through the harmonic penalty [24]. To model the marginal price for harmonic injection, the harmonic impedance is assumed to be constant [24]; however, the impedance of the power system cannot be constant as the impedance depends on the operation and load condition. Peng et al. [24] developed a novel harmonic pricing model based on harmonic costs and the effects of excessive harmonic current. By developing the pricing model, the economic losses due to harmonics can be compensated; however, this should be discussed when formulating the contract between the utility and customers. Once the harmonic limits are part of the contract document and the harmonic penalty model is in place, it will help the customer to control their emission level of the harmonic current to reduce the harmonic bills.

\section{Materials and Methods}

A power system with harmonic distortions that are not monitored accurately can cause the challenges of harmonic source detection between the utility and the customers. The harmonic monitoring system is developed using a flowchart that describes all the procedures to be followed by the utilities during the planning phase of drafting the ESA. The system was developed based on the national and international standards that specify harmonic limits. The method and calculation of harmonic apportioning is not part of this paper. The harmonic monitoring is determined by national and international harmonic standards and ESA, as shown in the research design in Figure 1.

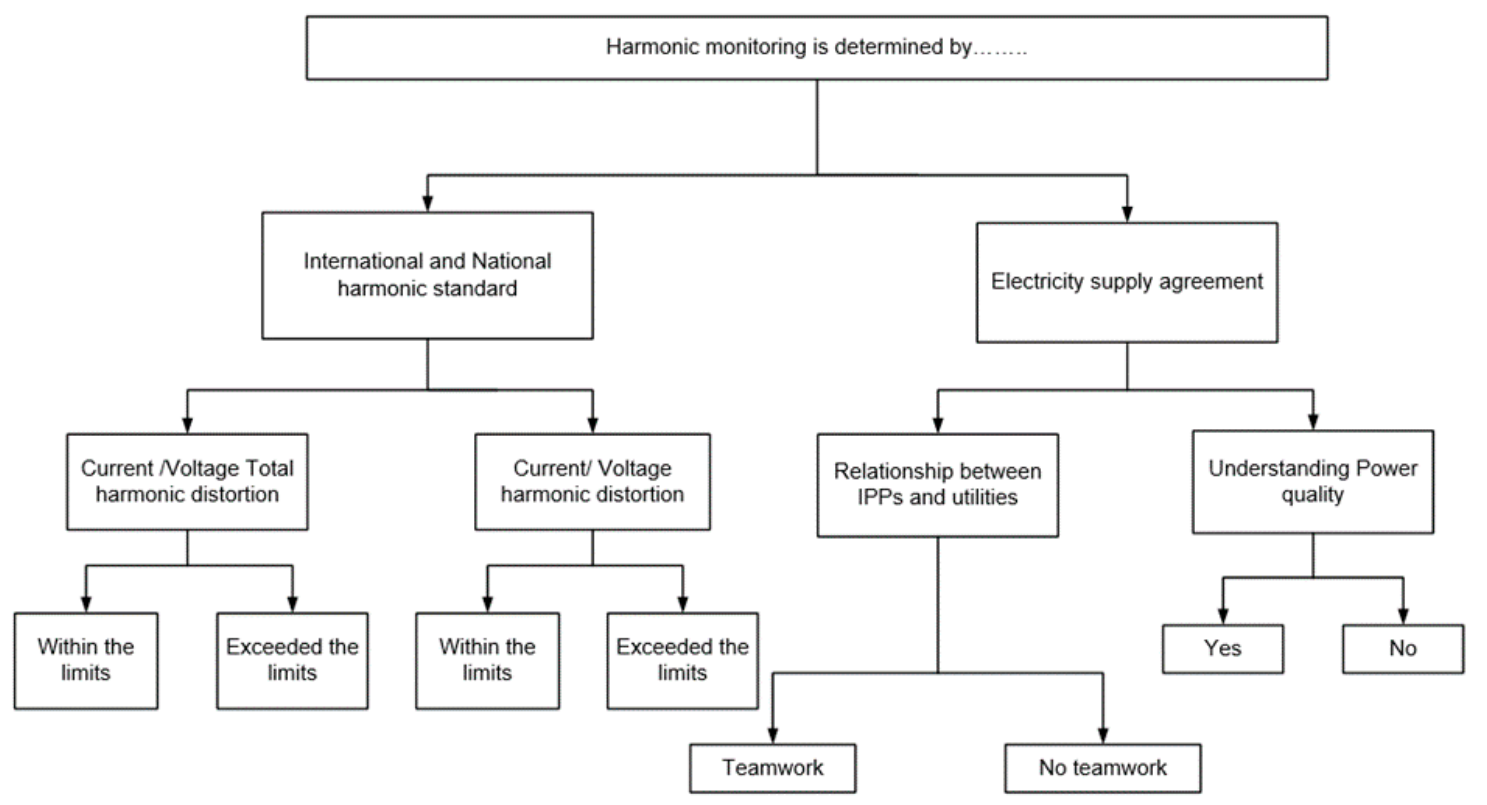

Figure 1. Dendrogram deductive research design for harmonic monitoring. 
This approach is based on practical challenges of a scenario where three customers with different operating load conditions are connected at the PCC. The PCC has a higher THD that exceeds the limit specified by the standards. This harmonic distortion is affecting the equipment of the customers, it is difficult to find the source of harmonics at that point, and there is no harmonic limit set in the ESA. Therefore, it is ideal for the harmonic limit to be set during the planning phase and be a part of the ESA from the first stage. It is difficult to change the ESA at a later stage as this may require the utility to investigate before any amendment can be adapted.

According to Figure D.1 in Reference [12], a concerning emission evaluation procedure, how emission limits are addressed in contracts, is categorized in three stages. These stages only specify the harmonic limit of the three different customers, and the utility's harmonic limit is ignored as nothing is documented about it. However, the utility's background harmonics need to be monitored and well documented. Figure D.1 in Reference [12] is changed to accommodate the utility's background harmonics from upstream of the network to be specified according to standard procedures, as shown in Figure 2.

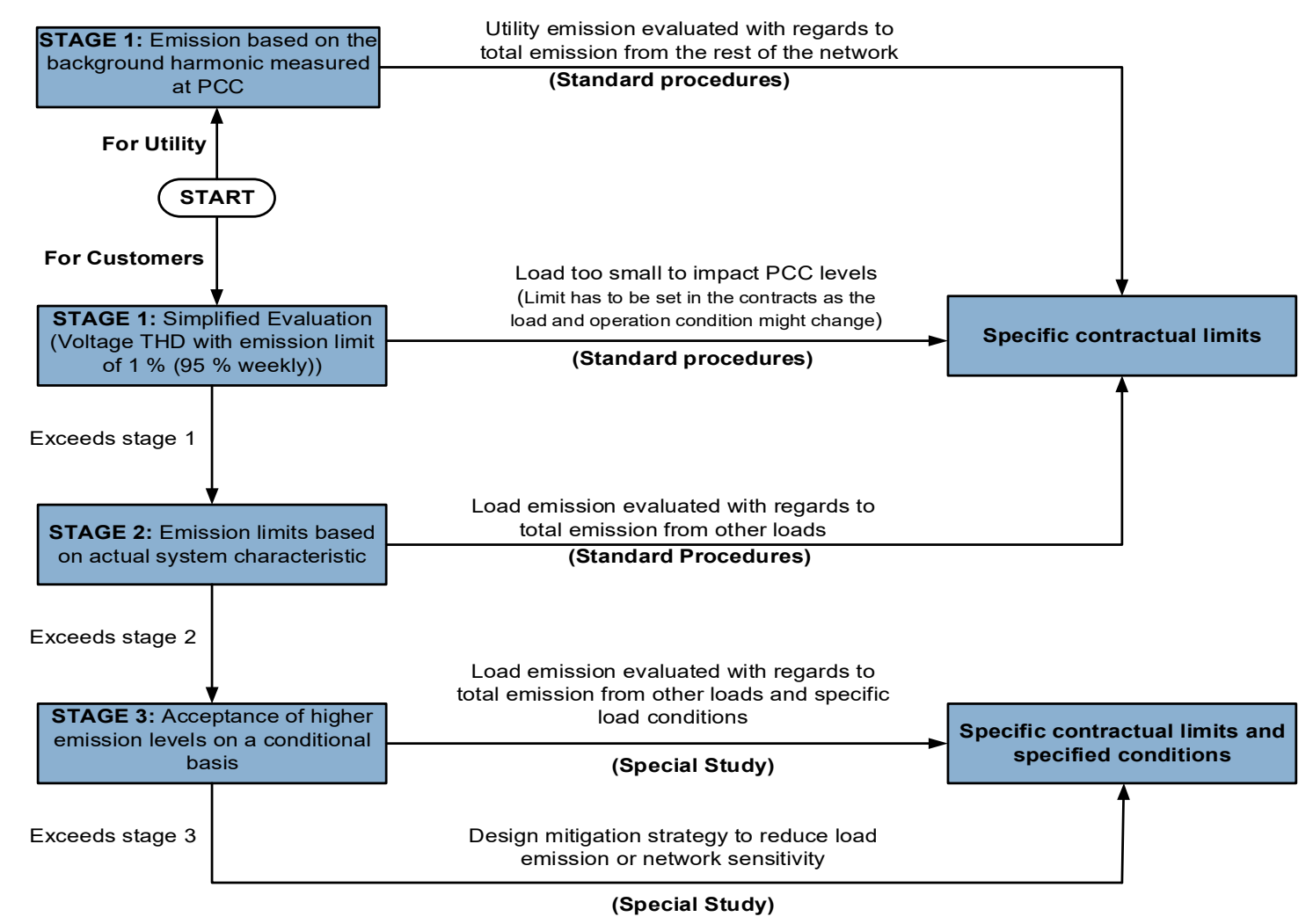

Figure 2. Illustration of the emission evaluation procedure and how emission limits are addressed in contracts for both parties.

Stage 1 on the customer side is also changed to have a specified contractual limit according to standard procedures. The load owner can decide to change the equipment or operation procedures without increasing the NMD of the load. At present, customers could install a rooftop solar photovoltaic (PV) system to reduce their electricity bill from the utility. This can change the harmonic parameter of the specific load.

Three stages need to be used for the development of the harmonic monitoring system. 


\subsection{The Harmonic Monitoring System Development Stages}

\subsubsection{Stage 1: Problem Identification}

It is a challenge to find the source of harmonics at the PCC where multiple customers are connected. Every PCC should have a PQ analyzer and a smart meter for LPUs, such as mines, factories, etc. This should be enforced by the regulator to the power utilities. It is also advisable for these customers to declare their non-linear loads with preliminary studies before signing the ESA. However, if this is not correctly implemented and monitored as per standards, utilities can still face challenges in finding customers responsible for harmonic contents in the network [53,54]. A clear specification of harmonic limits for each customer needs to be known and be part of the ESA. A contract can be used to solve the problems of harmonic content if defined properly. The customer can be given the maximum allowable in harmonic voltage or maximum allowable harmonic current injection at different harmonic frequencies. In most cases when the current distortion limits are within the specified limit, the voltage distortion limit should be met [55]. Once each customer is given a specified limit of current distortion, they can inject at the PCC, measurements can be done to determine whether the customer is within the harmonic limit given, and the specific customer can be notified in writing to remedy the problem if the harmonic limit is exceeded. This can be treated similarly to the NMD. Customers adhere to the NMD as there are penalties involved that are non-negotiable. The utility must be serious about harmonic limits as they bring about more challenges if not managed and monitored correctly [55].

\subsubsection{Stage 2: Objective to Solve the Problem}

The harmonic limit contents must be clearly said in contracts and understood by all parties. Measurement guidelines must be developed and agreed upon before the contract is signed. Measures must be put in place defining the processes to be followed once one of the parties does not honor the contract. Harmonic limits at the PCC must be defined in contracts according to the standards. Limits must be set per customer to resolve the issue of harmonic contents. Therefore, in solving the problem defined in stage 1 , the following questions need to be attended to:

1. What can be done to find the harmonic contents?

2. Who is the party responsible for the harmonic contents at the PCC?

3. What are the measurement principles of the harmonic contents per customer?

4. What are harmonic content limits per customer/utility and PCC?

5. How will the limits be achieved?

\subsubsection{Stage 3: Solutions}

When the measured harmonic content at the PCC is exceeded, three types of solutions should be taken into consideration by both parties, i.e., utilities and customers.

\section{Technical Solution}

The technical solution is usually the solution that both parties opt for according to the distribution code issued by the regulator. In cases where the harmonic limit at the PCC is exceeded, measurements need to be taken by both parties for a certain period agreed upon in the contract. The position of the equipment must be decided where the main measurement and backup measurement should be taken. Measuring equipment agreed upon in the contract should be correctly calibrated by an approved and registered company. Care should be taken that any equipment connected at the secondary winding of the voltage transducer does not generate harmonic currents. All customers with distributed power generators, as well as RES that inject harmonic current in the network which affects the harmonic voltage at the PCC, should be treated similarly. However, when the harmonic content exceeds the limits specified in the ESA, such customers shall be notified in writing monthly. In the case when the harmonic content is exceeded for three consecutive months, a penalty charge is affected and shall rest 
only when the exceeded harmonic content limit drops down below the initial value that was agreed on. The responsible party should be given three months to mitigate its contribution by supplying a harmonic filter, or any other mitigation methods, and bearing the costs thereof. There is currently no standard solution available that refers to specific months before the financial solution takes place. However, harmonic distortion causes the techno-economic losses that need to be recovered. The NMD has been managed based on three consecutive months and its implementation is successful [56]; thus, once the harmonic distortion takes up the initiative, this can drastically change the customer behavior towards the challenge. As the designing of a harmonic mitigation solution can be a lengthy process, the responsible party must handle the financial solution until mitigation takes place and the harmonic content is within the limit set. By so doing, parties involved will be serious about adhering to the condition specified under the ESA. It is important to control the customers who inject harmonics into the distribution network by applying the various mechanisms of rewards and punishment. Continuous monitoring of harmonic distortion and communication to the customers is needed. New applicants for electricity supply should be notified of the complications involved once the ESA conditions are not adhered to by giving an example of the existing contracts about harmonic content and exceeding the limits.

\section{Financial Solution}

It should be said in the contract agreement that the party who is responsible shall pay the penalty after three consecutive months of exceeding harmonic limits. The penalty payment should be processed similarly to that of the NMD applications. The harmonic penalty charge once introduced will have control with regards to the customers who injects the excessive harmonic higher than prescribed within standards, which will result in higher electricity monthly bill. The process of calculating the penalties is not part of this paper, as this is something that the national regulatory body of a specific country must agree upon with the utility. In the literature, different harmonic penalty models are suggested. However, no agreement has been reached yet toward the development of a global model to be used. Utilities should clarify clearly in contracts what should happen to other customers connected at the same PCC if their equipment has been affected by the inadequate quality of supply (QoS). The utilities must be responsible to manage the network in such a manner as to ensure that voltage distortion is still within contracted limits and adheres to the PQ standards prescribed by the electricity regulatory body of the specific country. In cases whereby the harmonic content which exceeds the limits is from the utility itself, the same process should be followed to remedy the problem.

\section{Legal Solution}

There should be a clause in the contract agreement that states, in a case where the limits of harmonic distortion are exceeded and disputes arise, the process in which the disputes should be dealt with. In the contract, it should be said that the complaints from the customer should be in writing and this complaint letter should be kept for a minimum of three years. Figure 3 indicates the three main stages of how to manage the harmonic contents to be used in developing a harmonic monitoring system.

The utility must take measurements of the voltage harmonic distortion at the PCC before any customer is connected at that point. Once the background harmonic at the PCC is known, during the planning phase, an overview is given of the remaining percentage that needs to be apportioned to the applications of the customers who are to be connected at that point. It can also show how many customers can be connected to the PCC. Today, the main factors that contribute to deciding the number of customers to be connected at the PCC are the transformer capacity and the maximum current carrying capacity of the conductors and clamps. In most cases, the utility can upgrade the transformer to a higher capacity transformer. It is crucial to consider the total voltage harmonic distortion of the PCC as a limiting factor for the number of customers to be connected at the PCC. 


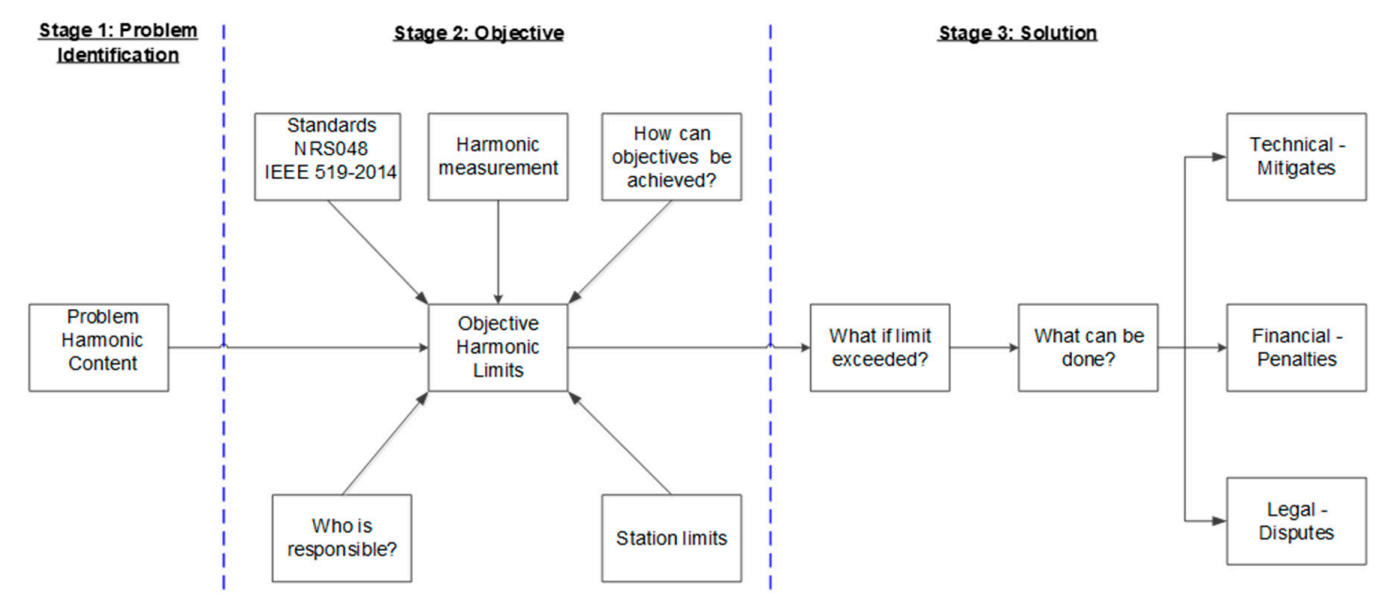

Figure 3. The concept of how to manage harmonic content.

\subsection{Contract Agreement Development}

The five stages for the development of contract agreement are specified in Figure 4.

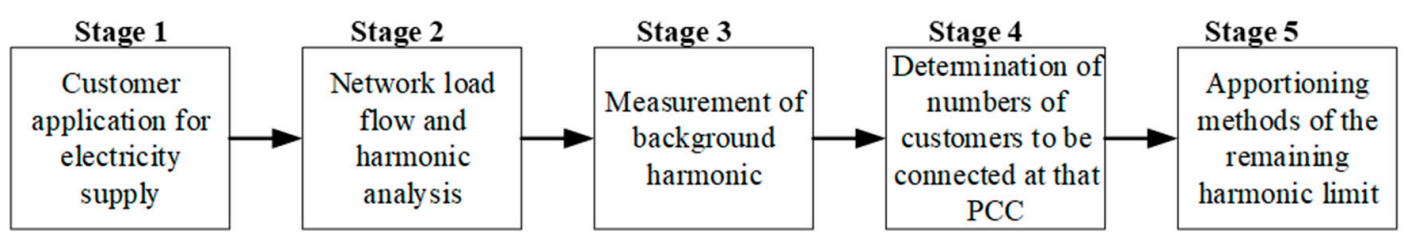

Figure 4. Five stages for the development of contract agreements.

These stages are described in detail as follows:

1. Stage 1-The customer approaches the power utility with the application for electricity supply, with their determined maximum demand required. It should become a requirement for the application to have the customer's harmonic content and the types of loads forming part of their plant. If this information is not part of the existing utility electricity supply application, the utility must review and amend the document. It is also important that the customers are notified by the utility to supply all the necessary information to have a comprehensive PQ analysis and obtain an accurately specified harmonic limit.

2. Stage 2-Planning engineers conduct the network load flow to check which part of the network has the capacity that is needed. Once the point of connection is found, PQ engineers need to determine the harmonic content of the customer. The PQ engineers should conduct the harmonic load flow analysis and suggest to the customers the specified harmonic limit based on the apportioning method that needs to be agreed upon.

3. Stage 3-The background harmonic at the PCC must be determined using the peak percentage recorded for the past twelve-month period from the Unipower/Vectograph data. It should be noted that the peak background harmonic is under no-load conditions, as well as born in mind when apportioning the specified harmonic limit of the utility at the PCC. The background harmonic might increase under load conditions.

4. Stage 4-The utility's forecast engineers should determine and supply the load forecast for the next five years. This shows the number of customers to be connected at a certain PCC.

5. Stage 5-The apportioning method of the harmonic content should be determined by the utility for each customer, and this depends on the data they have provided to the power utility. Customers should supply all the necessary information to help the utility to determine realistic and correct harmonic limits. 


\subsection{The Harmonic Monitoring Framework}

The framework of the harmonic monitoring system is given in Figure 5. The payment of a penalty is applied to each party which is responsible for causing the harmonic content higher than the allowable or agreed-upon limit in the contract. The fees for the penalty should be regulated by the national regulatory body where this method is to be applied. Thus, with this in place, both parties will take responsibility for their harmonic content seriously. The current research challenge of harmonic source detection will be resolved due to the penalties involved.

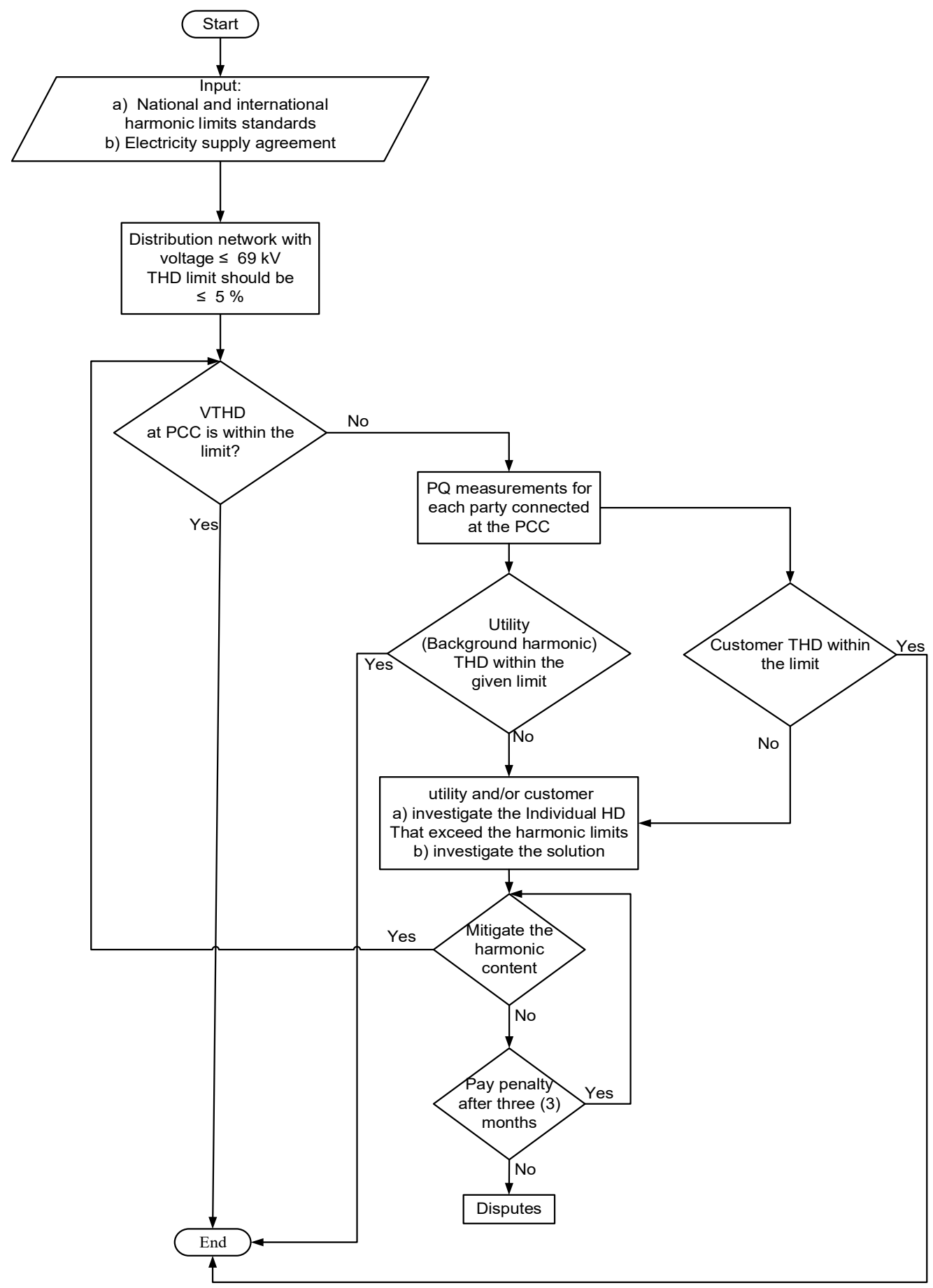

Figure 5. A proposed harmonic monitoring system. 
In case of dispute in Figure 5, then the responsible customer will have to compare the harmonic content profile extracted from its statistical PQ analyzer and compare it with the utility profile of the same period to determine the actual basis of the dispute. Furthermore, both PQ analyzers may require to be recalibrated and verify the earlier results with the current ones for accuracy in the search to settle the dispute.

\section{Results and Discussions}

A case study of an industrial network consisting of two mines, a 5 Megawatt (MW) solar PV plant, and commercial loads was used to confirm the harmonic monitoring framework. It has a $400 \mathrm{kV}$ slack bus with short-circuit power of Ssc $=10000$ Mega Volt Ampere (MVA), a short circuit current of Isc $=14.43 \mathrm{kA}$, and the $\mathrm{XR}$ ratio of 10 . The two mines are Mine A (open-pit), which consists of four three-phase 12-pulse rectifiers; and Mine B (underground), which consists of various three-phase 6-pulse Variable Speed Drives (VSDs). The Unipower measurement results are compared with the simulation case study in DIgSILENT. The individual and THD of the voltage is compared at certain busbars in the network as per measurements. Unipower PQ Secure gives reports that indicate whether the THD of the voltage is within the prescribed limit specified in Section 4.2.5 of the South African National Rationalization of Standards (NRS) 048-2-2007 which stipulates that the THD of the supply voltage, including all harmonics up to the order of 40 , should not exceed $4 \%$ for the High Voltage (HV), and the Medium Voltage (MV) networks should not exceed 8\%. It also highlights the individual harmonic distortion of voltage, whether it passes or fails the assessment. Once the value of individual harmonic distortion is within the limit prescribed by the national standard, it is then regarded as passed; when it exceeds the limit, it is regarded as failed. The Unipower meter results also give the event's history. The results used were from May 2019 to November 2019. The compatibility level for the HV and MV network used to analyze and compare the simulated and measured results is given in Table 1.

Table 1. Total harmonic distortion (THD) and compatibility level of individual harmonic distortion as per NRS 048-2-2007.

\begin{tabular}{ccc}
\hline Harmonic Order & Compatibility Level for $\mathbf{6 6} \mathbf{~ k V}$ & Compatibility Level for $\mathbf{3 3} \mathbf{~ k V}$ \\
\hline 5th & 3 & 6 \\
7th & 2.5 & 5 \\
11th & 1.7 & 3.5 \\
13th & 1.7 & 3 \\
17th & 1.2 & 2 \\
19th & 1.2 & 1.8 \\
23rd & 0.8 & 1.4 \\
25th & 0.8 & 1.3 \\
THD $(\%)$ & 4 & 8 \\
\hline
\end{tabular}

The results in bold define the THD and individual harmonic distortion of the current and voltage that exceeded the harmonic limits as set within the standards. It also indicates the individual harmonic orders that failed the compatibility level.

Table 2 gives the comparison of the Voltage Total Harmonic Distortion (VTHD) for the customers connected to the PCC. Customer B represents four individual customers, namely Mine B $66 \mathrm{kV}$, $66 \mathrm{kV}$ Node, PV plant $33 \mathrm{kV}$, and $33 \mathrm{kV}$ Busbar (two commercial loads). The other customer is Mine A $66 \mathrm{kV}$ with two feeders. The VTHD of each Mine A feeder gives a higher value than for Customer B $66 \mathrm{kV}$ feeder. The measurement is also able to check the THD of the utility side, which, in this case, has a lower THD than Mine A. From the simulation results, the THD for Mine A-No. 1 and $266 \mathrm{kV}$ Busbar exceeded the limit. The Simulation and measured results of Mine A-No.1 and $266 \mathrm{kV}$ Busbar summation exceeded the harmonic limit based on NRS 048-2-2007. 
Table 2. THD of the voltage for the customers connected at the point of common coupling (PCC).

\begin{tabular}{ccc}
\hline Busbar Name & THD Simulation Results (\%) & THD Measured Results (\%) \\
\hline PCC 66 kV-Customer B 66 kV & 3.55 & 2.935 \\
Mine A-No.1 66 kV Busbar & 4.10 & 3.640 \\
Mine A-No. 2 66 kV Busbar & 4.07 & 3.615 \\
Mine A-No.1 and 2 Summation & 5.78 & 5.13 \\
PCC 66 kV-Mine A No. 1 66 kV & - & 2.940 \\
PCC 66 kV-Mine A No. 2 66 kV & - & 2.945 \\
PCC 66 kV-Mine A No. 1 and 2 & & 4.16 \\
Summation & & \\
\hline
\end{tabular}

Table 3 gives Customer B VTHD to determine the highest contributor among these customers. The customers within Customer B who are a source of harmonic (has a load which injects harmonics) is the PV plant $33 \mathrm{kV}$ and mine B $66 \mathrm{kV}$. The percentages of VTHD at Mine B $66 \mathrm{kV}$ and $66 \mathrm{kV}$ Node exceeded the harmonic limit of $4 \%$ for measurement only.

Table 3. THD of the voltage for the customers within the Customer B category.

\begin{tabular}{ccc}
\hline Busbar Name & THD Simulation Results (\%) & THD Measured Results (\%) \\
\hline PV Plant 33 kV & 4.53 & 4.125 \\
$33 \mathrm{kV}$ Busbar & 4.51 & 4.120 \\
Mine B 66 kV & 3.62 & 4.255 \\
66 kV Node & 3.66 & $\mathbf{4 . 2 9 0}$ \\
\hline
\end{tabular}

The individual voltage harmonic distortion is compared for the two customers connected at the PCC in Tables 4-6. Customer B $66 \mathrm{kV}$ individual harmonic distortion of voltage for the 11th harmonic order simulated exceeded the limit and 23rd and 25th harmonic orders for both simulation and measured results also exceeded the limits set in NRS 048-2:2007 as shown in Table 4. However, the individual voltage harmonic distortion in Tables 5 and 6 of Mine A-No. 1 and $266 \mathrm{kV}$ shows that the 11th, 13th, 23rd, and 25th harmonic orders exceeded the limit and failed the standard compliance for both simulation and measured results.

Table 4. The voltage harmonic distortion comparison for Customer B $66 \mathrm{kV}$ measured and simulated results.

\begin{tabular}{cccccc}
\hline $\begin{array}{c}\text { Harmonic } \\
\text { Order }\end{array}$ & $\begin{array}{c}\text { Compatibility } \\
\text { Level }\end{array}$ & $\begin{array}{c}\text { 95\% Highest (\%) } \\
\text { Measured }\end{array}$ & $\begin{array}{c}\text { Compliance } \\
\text { Measured }\end{array}$ & $\begin{array}{c}\text { Simulated } \\
\text { Result }\end{array}$ & $\begin{array}{c}\text { Compliance } \\
\text { Simulated }\end{array}$ \\
\hline 5th & 3 & 1.33 & Passed & 0.02 & Passed \\
7th & 2.5 & 0.93 & Passed & 0.05 & Passed \\
11th & 1.7 & 1.37 & Passed & $\mathbf{1 . 7 3}$ & Failed \\
13th & 1.7 & 1.60 & Passed & 1.50 & Passed \\
17th & 1.2 & 0.23 & Passed & 0.06 & Passed \\
19th & 1.2 & 0.08 & Passed & 0.02 & Passed \\
23rd & 0.8 & $\mathbf{1 . 2 1}$ & Failed & $\mathbf{1 . 1 1}$ & Failed \\
25th & 0.8 & $\mathbf{1 . 2 1}$ & Failed & $\mathbf{1 . 0 2}$ & Failed \\
\hline
\end{tabular}


Table 5. The voltage harmonic distortion comparison for Mine A-No. $166 \mathrm{kV}$ Busbar measured and simulated results.

\begin{tabular}{cccccc}
\hline $\begin{array}{c}\text { Harmonic } \\
\text { Order }\end{array}$ & $\begin{array}{c}\text { Compatibility } \\
\text { Level }\end{array}$ & $\begin{array}{c}\text { 95\% Highest (\%) } \\
\text { Measured }\end{array}$ & $\begin{array}{c}\text { Compliance } \\
\text { Measured }\end{array}$ & $\begin{array}{c}\text { Simulated } \\
\text { Result }\end{array}$ & $\begin{array}{c}\text { Compliance } \\
\text { Simulated }\end{array}$ \\
\hline 5th & 3 & 1.30 & Passed & 0.01 & Passed \\
7th & 2.5 & 0.90 & Passed & 0.01 & Passed \\
11th & 1.7 & $\mathbf{1 . 8 3}$ & Failed & $\mathbf{2 . 1 8}$ & Failed \\
13th & 1.7 & $\mathbf{2 . 0 2}$ & Failed & $\mathbf{1 . 9 5}$ & Failed \\
17th & 1.2 & 0.22 & Passed & 0.01 & Passed \\
19th & 1.2 & 0.10 & Passed & 0 & Passed \\
23rd & 0.8 & $\mathbf{1 . 5 6}$ & Failed & $\mathbf{1 . 5 2}$ & Failed \\
25th & 0.8 & $\mathbf{1 . 5 1}$ & Failed & $\mathbf{1 . 4 0}$ & Failed \\
\hline
\end{tabular}

Table 6. The voltage harmonic distortion comparison for Mine A-No. $266 \mathrm{kV}$ Busbar measured and simulated results.

\begin{tabular}{cccccc}
\hline $\begin{array}{c}\text { Harmonic } \\
\text { Order }\end{array}$ & $\begin{array}{c}\text { Compatibility } \\
\text { Level }\end{array}$ & $\begin{array}{c}\text { 95\% Highest (\%) } \\
\text { Measured }\end{array}$ & $\begin{array}{c}\text { Compliance } \\
\text { Measured }\end{array}$ & $\begin{array}{c}\text { Simulated } \\
\text { Result }\end{array}$ & $\begin{array}{c}\text { Compliance } \\
\text { Simulated }\end{array}$ \\
\hline 5th & 3 & 1.33 & Passed & 0.01 & Passed \\
7th & 2.5 & 0.94 & Passed & 0.01 & Passed \\
11th & 1.7 & $\mathbf{1 . 8 3}$ & Failed & $\mathbf{2 . 1 8}$ & Failed \\
13th & 1.7 & $\mathbf{1 . 9 6}$ & Failed & $\mathbf{1 . 9 5}$ & Failed \\
17th & 1.2 & 0.23 & Passed & 0.01 & Passed \\
19th & 1.2 & 0.13 & Passed & 0 & Passed \\
23rd & 0.8 & $\mathbf{1 . 6 1}$ & Failed & $\mathbf{1 . 5 1}$ & Failed \\
25th & 0.8 & $\mathbf{1 . 4 7}$ & Failed & $\mathbf{1 . 3 9}$ & Failed \\
\hline
\end{tabular}

Tables 7 and 8 show that the individual voltage harmonic distortion is within the prescribed limit set by the standard except for the 23rd and 25th harmonic order. These could not be compared with simulation.

Table 7. The voltage harmonic distortion for PCC $66 \mathrm{kV}$-Mine A No. $166 \mathrm{kV}$ measured results.

\begin{tabular}{cccccc}
\hline $\begin{array}{c}\text { Harmonic } \\
\text { Order }\end{array}$ & $\begin{array}{c}\text { Compatibility } \\
\text { Level }\end{array}$ & $\begin{array}{c}\text { 95\% Highest (\%) } \\
\text { Measured }\end{array}$ & $\begin{array}{c}\text { Compliance } \\
\text { Measured }\end{array}$ & $\begin{array}{c}\text { Simulated } \\
\text { Result }\end{array}$ & $\begin{array}{c}\text { Compliance } \\
\text { Simulated }\end{array}$ \\
\hline 5th & 3 & 1.37 & Passed & - & - \\
7th & 2.5 & 0.93 & Passed & - & - \\
11th & 1.7 & 1.38 & Passed & - & - \\
13th & 1.7 & 1.59 & Passed & - & - \\
17th & 1.2 & 0.23 & Passed & - & - \\
19th & 1.2 & 0.08 & Passed & - & - \\
23rd & 0.8 & $\mathbf{1 . 2 1}$ & Failed & - & - \\
25th & 0.8 & $\mathbf{1 . 2 9}$ & Failed & - & - \\
\hline
\end{tabular}

Table 8. The voltage harmonic distortion for PCC 66 kV—Mine A No. $266 \mathrm{kV}$ measured results.

\begin{tabular}{cccccc}
\hline $\begin{array}{c}\text { Harmonic } \\
\text { Order }\end{array}$ & $\begin{array}{c}\text { Compatibility } \\
\text { Level }\end{array}$ & $\begin{array}{c}\text { 95\% Highest (\%) } \\
\text { Measured }\end{array}$ & $\begin{array}{c}\text { Compliance } \\
\text { Measured }\end{array}$ & $\begin{array}{c}\text { Simulated } \\
\text { Result }\end{array}$ & $\begin{array}{c}\text { Compliance } \\
\text { Simulated }\end{array}$ \\
\hline 5th & 3 & 1.37 & Passed & - & - \\
7th & 2.5 & 0.93 & Passed & - & - \\
11th & 1.7 & 1.35 & Passed & - & - \\
13th & 1.7 & 1.61 & Passed & - & - \\
17th & 1.2 & 0.23 & Passed & - & - \\
19th & 1.2 & 0.08 & Passed & - & - \\
23rd & 0.8 & $\mathbf{1 . 2 1}$ & Failed & - & - \\
25th & 0.8 & $\mathbf{1 . 2 8}$ & Failed & - & - \\
\hline
\end{tabular}


Tables 9 and 10 show that the measured results for the 23rd and 25th individual harmonic distortion exceeded the standard and failed compliance while the simulation results are within the limits. This can be because of the events that occurred in the plant at different periods, such as switching off the $66 \mathrm{kV}$ filters.

Table 9. The voltage harmonic distortion comparison for PV plant $33 \mathrm{kV}$ measured and simulated results.

\begin{tabular}{cccccc}
\hline $\begin{array}{c}\text { Harmonic } \\
\text { Order }\end{array}$ & $\begin{array}{c}\text { Compatibility } \\
\text { Level }\end{array}$ & $\begin{array}{c}\text { 95\% Highest (\%) } \\
\text { Measured }\end{array}$ & $\begin{array}{c}\text { Compliance } \\
\text { Measured }\end{array}$ & $\begin{array}{c}\text { Simulated } \\
\text { Result }\end{array}$ & $\begin{array}{c}\text { Compliance } \\
\text { Simulated }\end{array}$ \\
\hline 5th & 6 & 1.31 & Passed & 0.10 & Passed \\
7th & 5 & 1.43 & Passed & 0.20 & Passed \\
11th & 3.5 & 1.48 & Passed & 2.02 & Passed \\
13th & 3 & 1.92 & Passed & 2.07 & Passed \\
17th & 2 & 0.47 & Passed & 0.18 & Passed \\
19th & 1.8 & 0.28 & Passed & 0.26 & Passed \\
23rd & 1.4 & $\mathbf{2 . 2 0}$ & Failed & 0.43 & Passed \\
25th & 1.3 & $\mathbf{2 . 7 7}$ & Failed & 0 & Passed \\
\hline
\end{tabular}

Table 10. The voltage harmonic distortion comparison for $33 \mathrm{kV}$ Busbar measured and simulated results.

\begin{tabular}{cccccc}
\hline $\begin{array}{c}\text { Harmonic } \\
\text { Order }\end{array}$ & $\begin{array}{c}\text { Compatibility } \\
\text { Level }\end{array}$ & $\begin{array}{c}\text { 95\% Highest (\%) } \\
\text { Measured }\end{array}$ & $\begin{array}{c}\text { Compliance } \\
\text { Measured }\end{array}$ & $\begin{array}{c}\text { Simulated } \\
\text { Result }\end{array}$ & $\begin{array}{c}\text { Compliance } \\
\text { Simulated }\end{array}$ \\
\hline 5th & 6 & 1.34 & Passed & 0.10 & Passed \\
7th & 5 & 1.42 & Passed & 0.20 & Passed \\
11th & 3.5 & 1.48 & Passed & 2.02 & Passed \\
13th & 3 & 1.89 & Passed & 2.06 & Passed \\
17th & 2 & 0.48 & Passed & 0.18 & Passed \\
19th & 1.8 & 0.30 & Passed & 0.26 & Passed \\
23rd & 1.4 & $\mathbf{2 . 2 2}$ & Failed & 0.40 & Passed \\
25th & 1.3 & $\mathbf{2 . 7 4}$ & Failed & 0.01 & Passed \\
\hline
\end{tabular}

The results in Tables 11 and 12 show that 23rd and 25th harmonic orders exceeded the limit for both measured and simulation results. The simulated results of the 11th harmonic order also exceeded the limit.

Table 11. The voltage harmonic distortion comparison for Mine B $66 \mathrm{kV}$ measured and simulated results.

\begin{tabular}{cccccc}
\hline $\begin{array}{c}\text { Harmonic } \\
\text { Order }\end{array}$ & $\begin{array}{c}\text { Compatibility } \\
\text { Level }\end{array}$ & $\begin{array}{c}\text { 95\% Highest (\%) } \\
\text { Measured }\end{array}$ & $\begin{array}{c}\text { Compliance } \\
\text { Measured }\end{array}$ & $\begin{array}{c}\text { Simulated } \\
\text { Result }\end{array}$ & $\begin{array}{c}\text { Compliance } \\
\text { Simulated }\end{array}$ \\
\hline 5th & 3 & 1.08 & Passed & 0.02 & Passed \\
7th & 2.5 & 0.69 & Passed & 0.05 & Passed \\
11th & 1.7 & 1.07 & Passed & $\mathbf{1 . 7 2}$ & Failed \\
13th & 1.7 & 1.38 & Passed & 1.49 & Passed \\
17th & 1.2 & 0.27 & Passed & 0.06 & Passed \\
19th & 1.2 & 0.14 & Passed & 0.03 & Passed \\
23rd & 0.8 & $\mathbf{2 . 2 1}$ & Failed & $\mathbf{1 . 1 1}$ & Failed \\
25th & 0.8 & $\mathbf{3 . 2 0}$ & Failed & $\mathbf{1 . 0 2}$ & Failed \\
\hline
\end{tabular}


Table 12. The voltage harmonic distortion comparison for $66 \mathrm{kV}$ Node measured and simulated results.

\begin{tabular}{cccccc}
\hline $\begin{array}{c}\text { Harmonic } \\
\text { Order }\end{array}$ & $\begin{array}{c}\text { Compatibility } \\
\text { Level }\end{array}$ & $\begin{array}{c}\text { 95\% Highest (\%) } \\
\text { Measured }\end{array}$ & $\begin{array}{c}\text { Compliance } \\
\text { Measured }\end{array}$ & $\begin{array}{c}\text { Simulated } \\
\text { Result }\end{array}$ & $\begin{array}{c}\text { Compliance } \\
\text { Simulated }\end{array}$ \\
\hline 5th & 3 & 1.11 & Passed & 0.02 & Passed \\
7th & 2.5 & 0.69 & Passed & 0.05 & Passed \\
11th & 1.7 & 1.06 & Passed & $\mathbf{1 . 7 2}$ & Failed \\
13th & 1.7 & 1.37 & Passed & 1.49 & Passed \\
17th & 1.2 & 0.28 & Passed & 0.06 & Passed \\
19th & 1.2 & 0.15 & Passed & 0.03 & Passed \\
23rd & 0.8 & $\mathbf{2 . 2 1}$ & Failed & $\mathbf{1 . 1 1}$ & Failed \\
25th & 0.8 & $\mathbf{3 . 2 3}$ & Failed & $\mathbf{1 . 0 3}$ & Failed \\
\hline
\end{tabular}

The results show that it is possible to monitor harmonics based on the harmonic limit set in the standard used by the country. This is achieved by both simulation and measurement methods. As in most cases where the measured results failed compliance, the simulated results also failed. These customers have different operating and load conditions, they applied for electricity supply at different periods. These customers are faced with challenges of harmonic distortion at the PCC. These customers are blaming one another for harmonic distortion effects that cause malfunctioning of their equipment. Thus, it can be resolved through measurement and simulation as the customer with the highest percentage VTHD is the harmonic contributor.

Table 13 gives the simulated individual and THD of the voltage at different points within the network. It is seen that the VTHD of Mine-A No. $166 \mathrm{kV}$ Busbar, Mine-A No. $266 \mathrm{kV}$ Busbar, and Mine-A No. 1 and 2 Summation exceeded the limit. The individual harmonic distortion for the 11th, 13th, 23rd, and 25th harmonic orders of the $66 \mathrm{kV}$ busbar within the industrial network exceeded the harmonic limit.

Table 13. Harmonic distortion and THD of voltage at different busbars.

\begin{tabular}{|c|c|c|c|c|c|c|c|c|c|}
\hline \multirow{2}{*}{ Busbar Name } & \multicolumn{8}{|c|}{ Individual Harmonic Distortion (\%) } & \multirow{2}{*}{$\begin{array}{c}\text { THD } \\
(\%)\end{array}$} \\
\hline & 5 th & 7th & 11th & 13th & 17th & 19th & 23rd & 25th & \\
\hline PV Plant 33 kV & 0.10 & 0.20 & 2.02 & 2.07 & 0.18 & 0.26 & 0.43 & 0 & 4.53 \\
\hline $33 \mathrm{kV}$ Busbar & 0.10 & 0.20 & 2.02 & 2.06 & 0.18 & 0.26 & 0.40 & 0.01 & 4.51 \\
\hline PCC 66 kV-Customer B 66 kV & 0.02 & 0.05 & 1.73 & 1.50 & 0.06 & 0.02 & 1.11 & 1.02 & 3.55 \\
\hline Mine A-No. 166 kV Busbar & 0.01 & 0.01 & 2.18 & 1.95 & 0.01 & 0 & 1.52 & 1.40 & 4.10 \\
\hline Mine A-No. 266 kV Busbar & 0.01 & 0.01 & 2.18 & 1.95 & 0.01 & 0 & 1.51 & 1.39 & 4.07 \\
\hline Mine A-No. 1 and 2 Summation & 0.02 & 0.02 & 3.08 & 2.76 & 0.01 & 0 & 2.14 & 1.97 & 5.78 \\
\hline Mine B 66 kV & 0.02 & 0.05 & 1.72 & 1.49 & 0.06 & 0.03 & 1.11 & 1.02 & 3.62 \\
\hline 66 kV Node & 0.02 & 0.05 & 1.72 & 1.49 & 0.06 & 0.03 & 1.11 & 1.03 & 3.65 \\
\hline PCC 66 kV Busbar & 0.01 & 0.01 & 1.74 & 1.48 & 0.01 & 0 & 1.21 & 1.06 & 3.25 \\
\hline
\end{tabular}

Table 14 gives the simulated results of the individual and THD of the current for different parties (utility and customers) within the industrial network.

With the network range where the $I_{s c} / I_{L}$ is $<20$, as per Table 15, the Total Demand Distortion (TDD) should not exceed 5\%. All customers' Current Total Harmonic Distortion (ITHDs) is within the harmonic limits. The Solar PV individual current harmonic distortion percentages of the 23rd and 25th harmonic exceeded the limit. Mine A, individual harmonic distortion percentages of the 11th, 13th, 23rd, and 25th harmonic orders exceeded the limit, as well. 
Table 14. Harmonic distortion and THD of current for the utility and customers.

\begin{tabular}{cccccccc}
\hline & \multicolumn{7}{c}{ Harmonic Distortion (\%) } \\
\cline { 2 - 8 } $\begin{array}{c}\text { Harmonic } \\
\text { Order }\end{array}$ & Utility & \multicolumn{7}{c}{ Customers } \\
\cline { 2 - 8 } & & Mine A & Load 1 & Load 2 & Solar PV Farm & Load 3 & Mine B \\
\hline 5th & 0.008 & 0.022 & 0.056 & 0.051 & 0.367 & 0.010 & 0.306 \\
7th & 0.014 & 0.034 & 0.086 & 0.077 & 0.522 & 0.019 & 0.600 \\
11th & 1.020 & $\mathbf{2 . 9 4 4}$ & 0.594 & 0.526 & 0.987 & 0.417 & 1.197 \\
13th & 0.933 & $\mathbf{2 . 6 1 9}$ & 0.520 & 0.459 & 1.258 & 0.311 & 0.950 \\
17th & 0.005 & 0.018 & 0.036 & 0.031 & 0.173 & 0.010 & 0.287 \\
19th & 0.002 & 0.006 & 0.045 & 0.040 & 0.313 & 0.004 & 0.269 \\
23rd & 0.338 & $\mathbf{1 . 0 5 5}$ & 0.059 & 0.052 & $\mathbf{1 . 3 2 5}$ & 0.139 & 0.543 \\
25th & 0.347 & $\mathbf{1 . 0 1 9}$ & 0.002 & 0.002 & $\mathbf{0 . 7 7 8}$ & 0.119 & 0.477 \\
THD (\%) & 1.496 & 4.26 & 0.859 & 0.758 & 2.872 & 0.588 & 1.931 \\
\hline
\end{tabular}

Table 15. Current distortion limits for systems rated $120 \mathrm{~V}$ through $69 \mathrm{kV}$ [11]. Adapted and reprinted with permission from the Institute of Electrical and Electronics Engineers (IEEE). Copyright IEEE 2014. All rights reserved.

\begin{tabular}{ccccccc}
\hline \multicolumn{7}{c}{ Maximum Harmonic Current Distortion in Percent of $\mathbf{I}_{\boldsymbol{L}}$} \\
\hline \multicolumn{7}{c}{ Individual Harmonic Order (Odd Harmonics) } \\
$\mathbf{a}, \mathbf{b}$ \\
\hline $\mathrm{I}_{S C} / \mathrm{I}_{L}$ & $3 \leq h \leq 11$ & $11 \leq h \leq 17$ & $17 \leq h \leq 23$ & $23 \leq h \leq 35$ & $35 \leq h \leq 50$ & TDD \\
$<\mathbf{2 0}^{\mathbf{c}}$ & $\mathbf{4 . 0}$ & $\mathbf{2 . 0}$ & $\mathbf{1 . 5}$ & $\mathbf{0 . 6}$ & $\mathbf{0 . 3}$ & $\mathbf{5 . 0}$ \\
$20<50$ & 7.0 & 3.5 & 2.5 & 1.0 & 0.5 & 8.0 \\
$50<100$ & 10.0 & 4.5 & 4.0 & 1.5 & 0.7 & 12.0 \\
$100<1000$ & 12.0 & 5.5 & 5.0 & 2.0 & 1.0 & 15.0 \\
$>1000$ & 15.0 & 7.0 & 6.0 & 2.5 & 1.4 & 20.0 \\
\hline
\end{tabular}

a Even harmonics are limited to $25 \%$ of the odd harmonic limit above. ${ }^{\mathrm{b}}$ Current distortions that result in a dc offset, e.g., half-wave converters, are not allowed. ${ }^{c}$ All power generation equipment is limited to these values of current distortion, regardless of actual $\mathrm{I}_{S C} / \mathrm{I}_{L}$. Where $\mathrm{I}_{S C}=$ Maximmu short-circuit current at the PCC; $\mathrm{I}_{L}=$ Maximum demand load current (fundamental frequency component) at the PCC under normal load operating conditions.

\section{Conclusions}

Measurement of harmonic distortion becomes a challenge and expensive due to multiple harmonic sources connected at the PCC. This brought up the need for harmonic monitoring to be ongoing research proposing the financial solution of implementing a penalty charge to recover from the economic losses. The contribution of this paper is to propose a harmonic monitoring system, which can be used as a benchmark evaluation during the planning phase when the utility and the customers are setting up an ESA. The industrial case study was simulated in DIgSILENT and its results compared with the site measurement results of the industrial network. It was found that there is a correlation between the simulation and the measured results when determining compliance. If the proposed system is in place and harmonic limits are adapted as part of the ESA, this will enable smooth harmonic monitoring. It also helps in determining which individual harmonic frequency is exceeding the specified limit. This gives a technical solution to responsible customers when mitigation arises. The harmonic monitoring with this proposed system acts as proof of the financial solution of penalty payment to recover from the economic losses the utilities might be faced with. Utilities are recommended using a proposed harmonic monitoring system for their new customers, and harmonic distortion limits should be set up in their ESA as this can solve the problem of harmonic source detection when multiple customers are connected at the PCC.

The utilities are recommended following the proposed system, where the harmonic monitoring should be done monthly to avoid the uncertainty of different operating and load conditions. The outcome of the monitoring should be presented to the customers quarterly for harmonic mitigation and information purposes. Therefore, the proposed system aids utilities and customers to detect the 
source of harmonics and discuss the mitigation factors that are needed. Besides, the challenges of finding the methods for harmonic source detection are resolved.

Author Contributions: Conceptualization, R.S., K.M.A.-A.-E. and M.T.K.; methodology, R.S., K.M.A.-A.-E. and M.T.K.; software, R.S.; validation, R.S.; formal analysis, R.S.; investigation, R.S.; resources, R.S.; data curation, R.S.; writing — original draft preparation, R.S.; writing—review and editing, R.S., K.M.A.-A.-E. and M.T.K.; visualization, R.S.; supervision, K.M.A.-A.-E. and M.T.K.; project administration, K.M.A.-A.-E.; funding acquisition, K.M.A.-A.-E. and M.T.K. All authors have read and agreed to the published version of the manuscript.

Funding: This research was funded by the Centre for Distributed Power and Electronic Systems (CDPES), and the Faculty of Engineering and the Built Environment at the Cape Peninsula University of Technology.

Conflicts of Interest: The authors declare no conflict of interest.

\section{References}

1. Beleiu, H.G.; Beleiu, I.N.; Pavel, S.G.; Darab, C.P. Management of Power Quality Issues from an Economic Point of View. Sustainability 2018, 10, 2326. [CrossRef]

2. Rendroyoko, I.; Rusli, M. Development of Power Quality Control Procedures and Standards to Control the Connection of Non-linear Loads in Electric Power Systems. In Proceedings of the 22nd International Conference on Electricity Distribution, Stockholm, Sweden, 10-13 June 2013; Volume 231, pp. 1-6.

3. Khan, B.H. Non-Conventional Energy Resource; Tata McGraw-Hill Publishing: New Delhi, India, 2009.

4. Tiyou, T. The five biggest wind energy markets in Africa. Renew. Energy Focus 2016, 17, 218-220. [CrossRef]

5. Zhang, J. Research on Power Quality Problems Based on Smart Grid and New Energy Generation. In Proceedings of the 4th International Conference on Energy Science and Applied Technology, Chongqing, China, 29-30 December 2018; pp. 1-5.

6. Sinvula, R.; Abo-Al-Ez, K.M.; Kahn, M.T. Harmonic Source Detection Methods: A Systematic Literature Review. IEEE Access 2019, 7, 74283-74299. [CrossRef]

7. Bajaj, M.; Singh, A.K. Grid integrated renewable DG systems: A review of power quality challenges and state-of-the-art mitigation techniques. Int. J. Energy Res. 2019, 44, 26-69. [CrossRef]

8. Zobaa, A.F. Practical Solutions for Harmonics Problems Produced in the Distribution Networks. J. Electr. Syst. 2006, 2, 13-28.

9. Babu, V.; Manikandan, M. Total Harmonic Distortion Reduction for Power Quality Improvement: A Review. Int. J. Sci. Res. 2017, 6, 1681-1684.

10. Attia, H.A.; Fahmy, O.M. Harmonic Distortion Effects and Mitigation in Distribution Systems. J. Am. Sci. 2010, 6, 173-183.

11. IEEE Power and Energy Society. IEEE Recommended Practice and Requirements for Harmonic Control in Electric Power Systems; IEEE: New York, NY, USA, 2014; pp. 1-29.

12. National Energy Regulator of South Africa. Electricity Supply-Quality of Supply Part 4: Application Practices for Licensees; SABS: Pretoria, South Africa, 2009; pp. 1-57.

13. IEEE Power and Energy Society. IEEE Recommended Practice for Monitoring Electric Power Quality; IEEE: New York, NY, USA, 2019; pp. 1-98.

14. International Electrotechnical Committee. Electromagnetic Compatibility (EMC)_Part 3-6: Limits-Assessment of Emission Limits for the Connection of Distorting Installations to MV, HV and EHV Power Systems; International Electrotechnical Committee: Geneva, Switzerland, 2013.

15. IEEE Power and Energy Society. IEEE Recommended Practice for Power Quality Data Interchange Format (PQDIF); IEEE: New York, NY, USA, 2019; pp. 1-185.

16. National Energy Regulator of South Africa. Electricity Supply-Quality of Supply Part 2: Voltage Characteristics, Compatibility Levels, Limits and Assessment Methods; SABS: Pretoria, South Africa, 2007; pp. 1-42.

17. Bollen, M.; Baumann, P.; Beyer, Y.; Castel, R.; Esteves, J.; Faias, S.; Friedl, W.; Larzeni, S.; Trhulj, J.; Villa, F.; et al. Guidelines for Good Practice on Voltage Quality Monitoring. In Proceedings of the 22nd International Conference on Electricity Distribution, Stockholm, Sweden, 10-13 June 2013; Volume 369, pp. 1-4.

18. Houtepen, R.; Hulshorst, W.; Targosz, R. Regulatory Guidelines in Setting up a Voltage Quality Monitoring Framework. In Proceedings of the 22nd International Conference on Electricity Distribution, Stockholm, Sweden, 10-13 June 2013; Volume 4, pp. 1-4. 
19. Kilter, J.; Elphick, S.; Meyer, J.; Milanović, J.V. Guidelines for Power Quality Monitoring-Results from CIGRE/CIRED JWG C4.112. In Proceedings of the International Conference on Harmonics and Quality of Power (ICHQP), Bucharest, Romania, 25-28 May 2014; pp. 703-707.

20. Meyer, J.; Kilter, J. Case Studies for Power Quality Monitoring in Public Distribution Grids-Some results of Working Group CIGRE/CIRED C4.112. In Proceedings of the 9th International 2014 Electrical Power Quality Supply Reliability Conference, Rakvere, Estonia, 11-13 June 2014; pp. 85-92.

21. Zobaa, A.; Aleem, S.H.E.A.; Balci, M.E. Power System Harmonics-Analysis, Effects and Mitigation Solutions for Power Quality Improvement; IntechOpen: London, UK, 2018.

22. Wakileh, G.J. Power Systems Harmonics: Fundamentals, Analysis and Filter Design; Springer: New York, NY, USA, 2001.

23. Dugan, R.C.; McGranaghan, M.F.; Santoso, S.; Beaty, H.W. Electrical Power Systems Quality, 2nd ed.; McGraw-Hill: New York, NY, USA, 2003; Volume 1.

24. Peng, Y.; Tao, S.; Xu, Q.; Xiao, X. Harmonic Pricing Model Based on Harmonic Costs and Harmonic Current Excessive Penalty. In Proceedings of the 2nd International Conference on Artificial Intelligence, Management Science and Electronic Commerce (AIMSEC), Dengleng, China, 8-10 August 2011; pp. 4011-4014.

25. Kamenka, A. Six Tough Topics about Harmonic Distortion and Power Quality Indices in Electric Power Systems; The Schaffner Group: Luterbach, Switzerland, 2014.

26. Gandoman, F.H.; Aleem, S.H.E.A.; Jurado, F.; Ahmadi, A.; Shamkhani, K.; Ali, Z.M. A methodology for imposing harmonic distortion's penalty in customers bill. Electr. Power Syst. Res. 2020, 183, 106268. [CrossRef]

27. National Energy Regulator of South Africa. Distribution Network Code; NERSA: Germiston, South Africa, 2019. Available online: https://nersa.org.za/dsitribution-grid-code/ (accessed on 30 May 2020).

28. Electricity Control Board. Transmission Grid Code: Electricity Act 2007. Available online: http://www.lac. org.na/laws/2018/6731.pdf (accessed on 30 May 2020).

29. Electricity Control Board. Distribution Grid Code: Electricity Act 2007. Available online: http://www.lac.org. na/laws/2018/6730.pdf (accessed on 30 May 2020).

30. Thakur, P. Load Distribution and VFD Topology Selection for Harmonic Mitigation in an Optimal Way. IEEE Trans. Ind. Appl. 2020, 56, 48-56. [CrossRef]

31. Asheibi, A.; Stirling, D.; Soetanto, D. Analyzing Harmonic Monitoring Data Using Data Mining. In Proceedings of the 5th Australasian Data Mining Conference, Sydney, Australia, 29-30 November 2006; Volume 61, pp. 63-68.

32. Muzi, F.; Barbati, M. A Real-Time Harmonic Monitoring Aimed at Improving Smart Grid Power Quality. In Proceedings of the IEEE International Conference on Smart Measurements for Future Grids, Bologna, Italy, 14-16 November 2011; pp. 95-100.

33. Hamoud, G.; El-Nahas, I. Assessment of customer supply reliability in performance-based contracts. IEEE Trans. Power Syst. 2003, 18, 1587-1593. [CrossRef]

34. Council of European Energy Regulators. 5th CEER Benchmarking Report on Quality of Electricity Supply-2011; CEER: Brussels, Belgium, 2012; Available online: https://www.ceer.eu/documents/104400/-/-/0f8a1aca-91399bd4-e1f5-cdbdf10c4609 (accessed on 1 June 2020).

35. Nascimento, C.F.; Oliveira, A.A.; Goedtel, A.; Dietrich, A.B. Harmonic distortion monitoring for nonlinear loads using neural-network-method. Appl. Soft Comput. 2013, 13, 475-482. [CrossRef]

36. Stanescu, C.; Gal, S.; Widmer, J.; Pispiris, C. Power Quality Monitoring Systems in Romanian Electricity Market. In Proceedings of the International Symposium on Power Electronics, Electrical Drives, Automation and Motion, Ischia, Italy, 11-13 June 2008; pp. 1394-1397.

37. Farhat, C.J. Power quality monitoring and analysis. In Proceedings of the International Conference of Energy Management and Power Delivery, Singapore, 5 March 1998; pp. 1-4.

38. Olechiw, W.J.; Sabin, D.D.; Dimitriu, C.; Doherty, F.; McLeod, G. Power Quality Monitoring Systems more Information than just Waveforms and Events. In Proceedings of the 16th International Conference on Harmonics and Quality of Power (ICHQP), Bucharest, Romania, 25-28 May 2014; pp. 512-516.

39. Chandler, T. Quality of power contracts. In Proceedings of the China International Conference on Electricity Distribution, Guangzhou, China, 10-13 December 2008; pp. 1-5. 
40. Stanescu, C.; Vatră, F.; Poida, A.; Postolache, P. Power Quality in Romanian Electricity Market. In Proceedings of the 9th International Conference on Electrical Power Quality and Utilisation, Barcelona, Spain, 9-11 October 2007; pp. 1-4.

41. Kagan, N.; Ferrari, E.L.; Matsuo, N.M.; Duarte, S.X.; Cavaretti, J.L.; Tenório, A.; Souza, L.R. A methodology for monitoring harmonic distortions in electric power distribution systems. In Proceedings of the 2002 10th International Conference on Harmonics and Quality of Power (ICHQP), Rio de Janeiro, Brazil, 6-9 October 2002; Volume 1, pp. 322-327.

42. Kulkarni, H.; Bharadwaj, D. Online Harmonic Monitoring, Assessment and Control with AMR on Smartphone. Procedia Comput. Sci. 2015, 70, 92-98. [CrossRef]

43. Wang, T.; Li, Y.; Deng, Z.; Liu, Y.; Li, Y.; Tan, M.; An, Z. Implementation of state-wide power quality monitoring and analysis system in China. In Proceedings of the IEEE Power and Energy Society General Meeting, Portland, OR, USA, 5-10 August 2018; pp. 1-5.

44. Vlahinic, S.; Brnobić, D.; Stojković, N. Indices for Harmonic Distortion Monitoring of Power Distribution Systems. IEEE Trans. Instrum. Meas. 2009, 58, 1771-1777. [CrossRef]

45. Broshi, A. Monitoring power quality beyond EN 50160 and IEC 61000-4-30. In Proceedings of the 9th International Conference Electrical Power Quality and Utilisation, Barcelona, Spain, 9-11 October 2007; pp. 1-6.

46. Broshi, A. Monitoring Power Quality beyond EN 50160 and IEC 61000-4-30. In Proceedings of the IEEE Power Engineering Society Conference and Exposition in Africa-PowerAfrica, Johannesburg, South Africa, 16-20 July 2007; pp. 1-7.

47. Yildirim, O.; Eristi, B.; Eristi, H.; Unal, S.; Erol, Y.; Demir, Y. FPGA-based online power quality monitoring system for electrical distribution network. J. Int. Meas. Confed. 2018, 121, 109-121. [CrossRef]

48. Singh, R.R.; Yash, S.M.; Subham, S.C.; Indragandhi, V.; Vijayakumar, V.; Saravanan, P.; Subramaniyaswamy, V. IoT embedded cloud-based intelligent power quality monitoring system for industrial drive application. Future Gener. Comput. Syst. 2020, 112, 884-898. [CrossRef]

49. Ahmad, B.A.; Elsheikh, H.H.; Fadoun, A. Review of Power Quality Monitoring Systems. In Proceedings of the 15th International Conference on Industrial Engineering and Operations Management, Dubai, UAE, 3-5 March 2015; pp. 1-8.

50. Milanovic, J.V.; Meyer, J.; Ball, R.F.; Howe, W.; Preece, R.; Bollen, M.H.J.; Elphick, S.; Cukalevski, N. International Industry Practice on Power-Quality Monitoring. IEEE Trans. Power Deliv. 2013, 29, 934-941. [CrossRef]

51. Bingham, R.P. Measurement instruments for power quality monitoring. In Proceedings of the 2008 IEEE/PES Transmission and Distribution Conference and Exposition, Chicago, IL, USA, 21-24 April 2008; IEEE: Piscataway, NJ, USA, 2018; pp. 1-3.

52. Unruh, T.D. Application techniques for power quality monitoring. In Proceedings of the IEEE/PES Transmission and Distribution Conference and Exposition, Chicago, IL, USA, 21-24 April 2008; pp. 1-2.

53. Forum of Regulators. Report on Power Quality of Electricity Supply to the Consumers; Forum of Regulators: New Delhi, India, 2018.

54. Tang, K.; Shen, C. Method for detecting harmonic responsibility misjudgements based on waveform correlation analysis. IET Gener. Transm. Distrib. 2019, 13, 1545-1554. [CrossRef]

55. IEEE Power and Energy Society. IEEE Recommended Practice for Conducting Harmonic Studies and Analysis of Industrial and Commercial Power Systems; IEEE: New York, NY, USA, 2018; pp. 1-79.

56. ESKOM. Notified Maximum Demand Rules; ESKOM: Johannesburg, South Africa, 2009; Available online: http://www.eskom.co.za/CustomerCare/Tariffs_AndCharges/Documents/Notified_maximum_demand_ rules_Rev021.pdf (accessed on 2 June 2020).

(C) 2020 by the authors. Licensee MDPI, Basel, Switzerland. This article is an open access article distributed under the terms and conditions of the Creative Commons Attribution (CC BY) license (http://creativecommons.org/licenses/by/4.0/). 